\title{
Potential probiotic characterization of Lactobacillus reuteri from traditional Chinese highland barley wine and application for room-temperature-storage drinkable yogurt
}

\author{
Su Chen, ${ }^{1}$ Lin Chen, Lie Chen, Xueliang Ren, Hongjuan Ge, Baolei Li, Guanghui Ma, Xueqin Ke, Jun Zhu, \\ $\mathrm{Li} \mathrm{Li}$, Yuhong Feng, and Yanjun Li \\ Research and Development Department, Hangzhou Wahaha Technology Co. Ltd., Hangzhou 310018, China
}

\begin{abstract}
The aim of this study was to select probiotic strains that could be used in drinkable yogurt to yield viable cells following storage at room temperature (RT). The uniquely high altitude conditions in Tibet and the alcoholic environment of certain products, such as the highland barley wine homemade in Tibet, may induce unusual characteristics of microbial strains. A total of 27 lactic acid bacteria were isolated from homemade highland barley wines. One strain, Lactobacillus reuteri WHH1689, demonstrated no ability for lactose utilization, exhibited a high survival rate during storage at RT in drinkable yogurts, and produced very weak post-acidification. This strain showed great resistance to conditions simulating the gastrointestinal tract, including strong adherence to HT-29 cells and inhibitory activity against Escherichia coli, Shigella flexneri, Salmonella paratyphi $\beta$, and Staphylococcus aureus. A dextran sulfate sodium (DSS)-induced mouse model was used to evaluate the in vivo influence of $L b$. reuteri WHH1689 on the intestinal flora and showed that strain WHH1689 increased viable counts of bifidobacteria in feces of mice. The probiotic strain selected in this study - with its high survival at RT and lack of serious post-acidification problems - may provide significant improvements for dairy industry products by extending the storage time of dairy products with living cells.

Key words: Lactobacillus, highland barley wine, lactose utilization, room temperature storage, postacidification
\end{abstract}

\section{INTRODUCTION}

Probiotics are nonpathogenic microorganisms that exert a positive health benefit on the host when in-

Received November 15, 2017.

Accepted March 11, 2018.

${ }^{1}$ Corresponding author: chensu@wahaha.com.cn gested in an adequate amount, according to the FAO/ WHO (2006). This definition was recently revised and accepted after minor grammatical modifications as "live microorganisms that, when administered in adequate amounts, confer a health benefit on the host" (Hill et al., 2014). Most probiotic bacteria are lactic acid bacteria $(\mathbf{L A B})$ and, among them, Lactobacillus is one of the most common genera (Argyri et al., 2013). In recent years, probiotic LAB have received increasing attention because of their long history of safe use and potential therapeutic benefits for human health. Probiotics affect human health mainly by regulating the gastrointestinal microbiota (Saad et al., 2013), and the best vehicles for the delivery of viable probiotics to the human gut are dairy foods (Hill et al., 2017).

According to the scientific community, probiotic counts should exceed the minimum value of $6 \log \mathrm{cfu} /$ $\mathrm{mL}$ to confer potential health benefits (Nualkaekul et al., 2012). In the dairy industry, maintaining viability of probiotic bacteria in foods throughout storage is a constant challenge (Batista et al., 2015). Fermented products with living probiotic cells are normally transported and stored at 4 or $10^{\circ} \mathrm{C}$ because low temperatures inhibit the metabolism of bacteria and suppress post-acidification and, hence, product deterioration. Myriad organic acids are produced by the LAB, including those in yogurt, and the persistent production of acid leads to high post-acidification (Shah, 2000). Even post-acidification occurring during chilled storage results in a short shelf life and inhibits the viability of other probiotics, including Bifidobacterium (Wang et al., 2013). To delay post-acidification, inulin was found to be effective in sheep milk yogurt (Balthazar et al., 2016). Storage of fermented products at low temperature increases the cost of transport and limits the market economically. Moreover, refrigerated products are uncomfortable for most Asians to ingest because drinking refrigerated products is not common in Asian culture. Lactic acid bacteria that could survive at room temperature (RT) during transport and storage of fermented products without serious post-acidification 
would be a huge improvement for the dairy industry by extending the storage time of products with living cells.

The Tibetan Plateau, generally called "the roof of the world" because of its very high altitude, is characterized by its extreme environment. Highland barley, the main grain crop on the Tibetan Plateau, can be made into a variety of conventional foods, including fried noodles (i.e., zanba) and wines (Zhong et al., 2016). Homemade highland barley wine may spontaneously undergo a secondary malolactic fermentation step by LAB (Mesas et al., 2011). In the Shigatse area of Tibet, the average temperatures are above $10^{\circ} \mathrm{C}$ from May to October, and the daytime temperature can reach $20^{\circ} \mathrm{C}$ (Jiang et al., 2009). In this study, we isolated LAB from homemade highland barley wines collected in August from the Shigatse area, and Lactobacillus reuteri WHH1689 was screened for later experimentation. This strain was identified from among the isolated LAB. Because this strain lacked lactose utilization ability, it would not cause post-acidification during RT storage and thus was selected for further experiments. First, we tested the potential application of this strain in drinkable yogurt during storage at room temperature. Then, we evaluated the survivability of the strain in drinkable yogurt and extent of post-acidification. Because of the promising in vitro probiotic characteristics of this strain, we further examined the in vivo regulatory effect on intestinal flora in a mouse model.

\section{MATERIALS AND METHODS}

\section{Microorganisms and Cell Line}

Lactobacillus rhamnosus GG (LGG) and Lactobacillus casei strain Shirota $(\mathbf{L c S})$ were isolated separately from commercial fermented milk products (Yili, Inner Mongolia, China; and Yakult, Shanghai, China). A human colon adenocarcinoma cell line (HT-29) was purchased from Cell Institute of Chinese Academy of Sciences (Shanghai).

\section{Isolation of LAB from Highland Barley Wines}

Four samples (100 g each) of homemade highland barley wine were collected from local homes, with the residents' permission, in the Shigatse area of Tibet. Initially, $10 \mathrm{~g}$ of each sample was suspended in $100 \mathrm{~mL}$ of sterile saline and mixed thoroughly. Serial dilutions $\left(10^{-1}\right.$ to $\left.10^{-4}\right)$ were performed, and $100-\mu \mathrm{L}$ aliquots from each dilution were spread-plated onto de Man, Rogosa, and Sharpe (MRS) agar (Oxoid Ltd., Basingstoke, UK) and incubated at $37^{\circ} \mathrm{C}$ for 48 to $72 \mathrm{~h}$ anaerobically. Six to 7 colonies with different morphologies were randomly isolated from MRS agar plates for each sample. These isolates were submitted to analyses including Gram staining, morphology, and catalase activity (Garcia et al., 2016). Gram-positive, catalase-negative colonies were further stored at $-80^{\circ} \mathrm{C}$ in MRS broth (Oxoid Ltd.) containing $25 \%$ glycerol for further studies.

\section{Selection of LAB Lacking Lactose Utilization Ability}

To determine which LAB showed reduced levels of post-acidification in yogurt, 27 isolates were added to sterile $10 \%$ skim milk and incubated at $37^{\circ} \mathrm{C}$ for 3 mo. Milk curdled by fermentation was subsequently observed.

\section{Identification and Phylogenetic Analysis of the $L A B$ Isolate}

Bacterial genomic DNA of LAB was extracted using a Genomic DNA extraction kit (Sangon Biotech, Shanghai, China) according to the manufacturer's instructions. For the detection of $16 \mathrm{~S}$ rRNA gene sequences, the following primers were used: 27F: 5'-AGAGTTTGATCCTGGCTCAG-3', and 1492R: 5'-GGTTACCTTGTTACGACTT-3'. The PCR program was as follows: $94^{\circ} \mathrm{C}$ for $4 \mathrm{~min}$, followed by 32 cycles at $94^{\circ} \mathrm{C}$ for $30 \mathrm{~s}, 56^{\circ} \mathrm{C}$ for $30 \mathrm{~s}, 72^{\circ} \mathrm{C}$ for $1 \mathrm{~min}$ $20 \mathrm{~s}$, with a final step at $72^{\circ} \mathrm{C}$ for $10 \mathrm{~min}$ (Guo et al., 2010; Garcia et al., 2016). The PCR product was subsequently sequenced (Sangon Biotech). The resulting sequence was aligned via the National Center for Biotechnology Information BLAST program (http:// blast.ncbi.nlm.nih.gov) to choose closely related strains and to identify the 16S rRNA gene sequence similarities of phylogenetic neighbors. Multiple alignment of $16 \mathrm{~S}$ rRNA nucleotide sequences from 13 species included in the analysis was generated using CLUSTAL_X (Larkin et al., 2007). The phylogenetic tree was constructed with Mega 5.0 (Tamura et al., 2011) using the neighborjoining method and a bootstrap value of 1,000 .

\section{Stability of Lb. reuteri WHH1689 in Products During Storage}

Lactobacillus reuteri WHH1689 was propagated in MRS broth overnight at $37^{\circ} \mathrm{C}$ followed by sub-culture and incubation for a further $18 \mathrm{~h}$. All cultures were harvested by centrifugation $\left(5,752 \times g, 10 \mathrm{~min}, 8^{\circ} \mathrm{C}\right)$ and the pellets were washed once in PBS, $\mathrm{pH}$ 7.4. A $1 \%$ inoculum of culture was aseptically distributed into $50-\mathrm{mL}$ portions of 2 commercial dairy products (UHTtreated drinkable yogurt) to obtain a final concentration 
of $10^{7}$ to $10^{8} \mathrm{cfu} / \mathrm{mL}$. The dairy products were UHT treated before we added $L b$. reuteri WHH1689. Cell counts, $\mathrm{pH}$, and acidity measurements were performed immediately after the addition and every week until 2 mo of storage at $28^{\circ} \mathrm{C}$ or $37^{\circ} \mathrm{C}$ (Balthazar et al., 2016). pH was measured by Seven Multi S40 (Mettler-Toledo, Greifensee, Switzerland). Acidity was calculated from the value measured by 905 Titrando (Metrohm, Herisau, Switzerland). Acidity $\left({ }^{\circ} \mathrm{T}\right)$ is the value of 0.1000 $\mathrm{mol} / \mathrm{L}$ of $\mathrm{NaOH}$ used to adjust the $\mathrm{pH}$ of a 100-g sample to $\mathrm{pH}$ 8.3. Acidity $\left({ }^{\circ} \mathrm{T}\right)$ was calculated as $\left(\mathrm{V}_{\mathrm{S}}-\mathrm{V}_{0}\right) \times$ $100 / \mathrm{M}_{\mathrm{S}}$, where $\mathrm{V}_{\mathrm{S}}$ is a volume of $0.1000 \mathrm{~mL} / \mathrm{L}$ of $\mathrm{NaOH}$ used to adjust the sample $\mathrm{pH}$ to $\mathrm{pH} 8.3, \mathrm{~V}_{0}$ is a volume of $0.1000 \mathrm{~mL} / \mathrm{L}$ of $\mathrm{NaOH}$ used to adjusted the water $\mathrm{pH}$ to $\mathrm{pH} 8.3$, and $\mathrm{M}_{\mathrm{S}}$ is grams of sample.

\section{In Vitro Acid and Bile Tolerance Test}

Gastric survival of the examined strain under conditions simulating the gastrointestinal tract was evaluated as previously described (Charnchai et al., 2016). Tolerance was initially screened by using low $\mathrm{pH}$ and simulated gastric juice. Briefly, bacterial cells from overnight $(18 \mathrm{~h})$ cultures were harvested $(5,752 \times g$, $\left.10 \mathrm{~min}, 8^{\circ} \mathrm{C}\right)$ and washed twice with PBS $(0.8 \% \mathrm{NaCl}$, $0.2 \% \mathrm{KCl}, 0.144 \% \mathrm{Na}_{2} \mathrm{HPO}_{4}, 0.024 \% \mathrm{KH}_{2} \mathrm{PO}_{4}, \mathrm{pH} 7.2$ ) before being resuspended in PBS solution and adjusted to $\mathrm{pH}$ of 2 and 3 . To evaluate resistance to simulated gastric juice, bacterial cells were harvested and washed as described above. The bacterial suspension was then resuspended in PBS solution containing $0.3 \%$ (wt/vol) pepsin (Sigma-Aldrich, St. Louis, MO) and adjusted to $\mathrm{pH}$ of 2 and 3. Resistance was assessed in terms of viable colony counts on MRS agar after incubation of bacterial suspensions at $37^{\circ} \mathrm{C}$ for 0 to $3 \mathrm{~h}$, reflecting the time spent by food in the stomach.

For resistance to conditions of the small intestine, bacterial cells prepared as above were resuspended in PBS solution containing $0.1 \%$ (wt/vol) pancreatin $(\mathrm{pH}$ 8 , Sigma-Aldrich) and PBS solution containing $0.3 \%$ or $0.5 \%$ (wt/vol) bile salt ( $\mathrm{pH} 8$, Oxoid Ltd.). The viable colony counts were determined after incubation at $37^{\circ} \mathrm{C}$ for 0 to $3 \mathrm{~h}$.

\section{In Vitro Adherence Assay}

The ability of the strains to adhere to human epithelial cells was investigated according to the method of Kim et al. (2009). Monolayers of HT-29 intestinal epithelial cells were prepared in RPMI-1640 (Sigma-Aldrich) supplemented with $10 \%$ fetal bovine serum (Sigma-Aldrich) in 24-well tissue culture plates (Sarstedt, Sarstedt, Germany) at a concentration of $0.5 \times 10^{6}$ cells/well. The cells were incubated with approximately $1 \times 10^{8} \mathrm{cfu} / \mathrm{mL}$ of the strains to be tested. After $2 \mathrm{~h}$ of incubation at $37^{\circ} \mathrm{C}$, the monolayers were washed 3 times with PBS. Adherent bacteria were detached by repeatedly pipetting with chilled $0.05 \%$ Triton X-100, diluted in sterile solution and then enumerated by counting on MRS agar plates. The assay was repeated twice for every strain and counts were performed in duplicate; LGG was used as a control.

\section{Antimicrobial Activity}

The ability of the candidate strain to inhibit the growth of pathogenic microorganisms was determined using the agar-well diffusion assay (Nami et al., 2014). Overnight cultures of the indicator strains (Escherichia coli CICC23689, Shigella flexneri CICC 21534, Salmonella paratyphi $\beta$ CICC 10437, Staphylococcus aureus CICC 10301) were used to inoculate nutrient broth agar at $37^{\circ} \mathrm{C}$. Fresh overnight $L b$. reuteri culture was harvested by centrifugation $\left(5,752 \times g, 10 \mathrm{~min}, 8^{\circ} \mathrm{C}\right)$ and resuspended in fresh MRS broth. Cell suspension samples $(100 \mu \mathrm{L})$ were pipetted into holes $(7 \mathrm{~mm})$ drilled in the agar plates containing pathogenic strains. The plates were then incubated at $37^{\circ} \mathrm{C}$ and examined after $24 \mathrm{~h}$ of incubation. Antimicrobial activity was recorded as growth-free inhibition zones ( $\mathrm{mm}$ ) around the well.

\section{Regulatory Effect of $L b$. reuteri on Intestinal Flora in a Dextran Sulfate Sodium-Induced Mouse Model}

Oral administration of the sulfated polysaccharide dextran sulfate sodium (DSS) to mice via drinking water induces colitis characterized by weight loss, bloody diarrhea, and loss of epithelial cells (Wirtz et al., 2017). We studied how the intestinal flora was affected by probiotics treatment in DSS-induced mice. Female ICR mice $(18-20 \mathrm{~g})$ were used and randomly divided into 6 groups (10 animals each). Mice were housed and fed in accordance with the Provisions and General Recommendations of Chinese Experimental Animal Administration Legislation. A control group (group 1), a colitis control group (group 5), and 4 groups of mice with DSS-induced colitis and treated with probiotics were administered. Normal saline $(0.2 \mathrm{~mL})$ in the 2 control groups or the tested bacteria strain $(0.2 \mathrm{~mL})$ was administered orally by orogastric tube once daily. Mice of group 1 received no probiotic treatment and no DSS. Group 2 mice were pretreated with $10^{7} \mathrm{cfu}$ per animal of Lb. reuteri WHH1689 for $14 \mathrm{~d}$. After the first $14 \mathrm{~d}, 5 \%$ DSS solution was administered instead of water, and oral gavage with WHH1689 was continued for another 

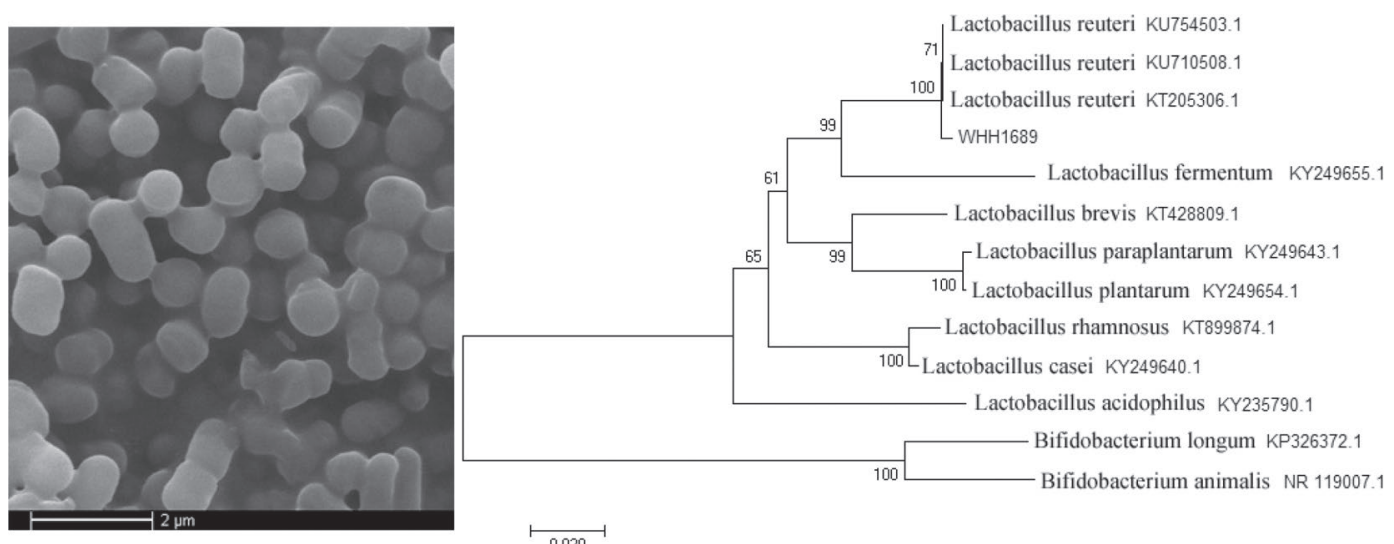

Figure 1. Scanning electron micrograph of Lactobacillus reuteri WHH1689 strain and the 16S rRNA phylogram of representative Lactobacillus strains, with an outgroup containing Bifidobacterium longum and Bifidobacterium animalis. Ribosomal RNA sequences for all strains but Lb. reuteri WHH1689 were obtained from the GenBank database.

14 d. Group 3 mice were treated similarly to group 2 mice except that $L b$. reuteri WHH1689 was dosed at $10^{8} \mathrm{cfu} /$ animal. Group 4 mice were treated similarly as group 2, except that $10^{7} \mathrm{cfu}$ of LcS was used instead of WHH1689. Group 5 mice (colitis control) were orally gavaged with sterile saline dilution for first $14 \mathrm{~d}$. After $14 \mathrm{~d}, 5 \%$ DSS solution was provided and oral gavage was continued. Group 6 mice, a treatment group, were orally gavaged with sterile saline dilution for the first 14 d. After $14 \mathrm{~d}, 10^{7} \mathrm{cfu}$ per animal of $L b$. reuteri WHH1689 was orally gavaged and the mice were dosed with $5 \%$ DSS. Fresh feces were collected, serially diluted, and plated on Lactobacillus Selective Agar (LBS), de Man, Rogosa, Sharpe Medium (MRS)+NNLP (nalidixic acid, neomycin sulfate, lithium chloride, and paramomycine sulfate), Violet Red Bile Dextrose Agar (VRBDA), Bile Esculin Agar (BEA), and Tryptose Sulfite Cycloserine Agar (TSC; all of these media were purchased from Hope Bio-Technology, Qingdao, China) to estimate the number of viable lactobacilli, bifidobacteria, enterobacteria, enterococci, and Clostridium perfringens, respectively (Zhang et al., 2014). The plates were incubated at $37^{\circ} \mathrm{C}$ for 24 or $48 \mathrm{~h}$, and results are reported as $\log _{10}$ $\mathrm{cfu} / 0.1 \mathrm{~g}$ of feces sample.

\section{Statistical Analysis}

Data were analyzed using SPSS Statistics (version 23, SPSS Inc., Chicago, IL). Statistical differences in multiple groups were determined by one-way ANOVA followed by multiple mean comparisons with Tukey's test. All numerical data were displayed as mean \pm standard deviation, and $P<0.05$ was considered statistically significant.

\section{RESULTS}

\section{Identification and Phylogenetic Analysis of the $L A B$ Isolate}

A total of 27 strains isolated from 4 highland barley wines were gram positive and catalase negative. All milk with the 27 strains were curded, except the milk with the WHH1689 strain, indicating that WHH1689 cannot ferment milk at $37^{\circ} \mathrm{C}$. Strain WHH1689 has a short rod-shaped morphology, as shown by scanning electron microscopy (Figure 1).

The partial 16S rRNA gene sequence of the WHH1689 strain, revealed to be 1,422 bp long, was deposited in the GenBank database with an accession number of KY963628. Phylogenetic analyses indicated that the WHH1689 strain belonged to the species Lactobacillus reuteri (Figure 1 ).

\section{Storage Stability of Lb. reuteri WHH1689 in Commercial Products}

It is very important for probiotics to survive in fermented products during shelf storage with either no or minimal post-acidification. Currently, products must be stored at refrigerated temperatures to maintain survival of the probiotics and inhibit post-acidification for 1 mo of shelf life. The main purpose of this study was to isolate a probiotic candidate that could survive in dairy food under room temperature storage without the texture of the product changing.

Lactobacillus reuteri WHH1689 was incorporated into dairy products ( 2 types of pasteurized fermented milks, one a thin drinkable yogurt and the other a thicker drinkable yogurt) at $28^{\circ} \mathrm{C}$ or $37^{\circ} \mathrm{C}$ for 1 to 2 mo. Strain 

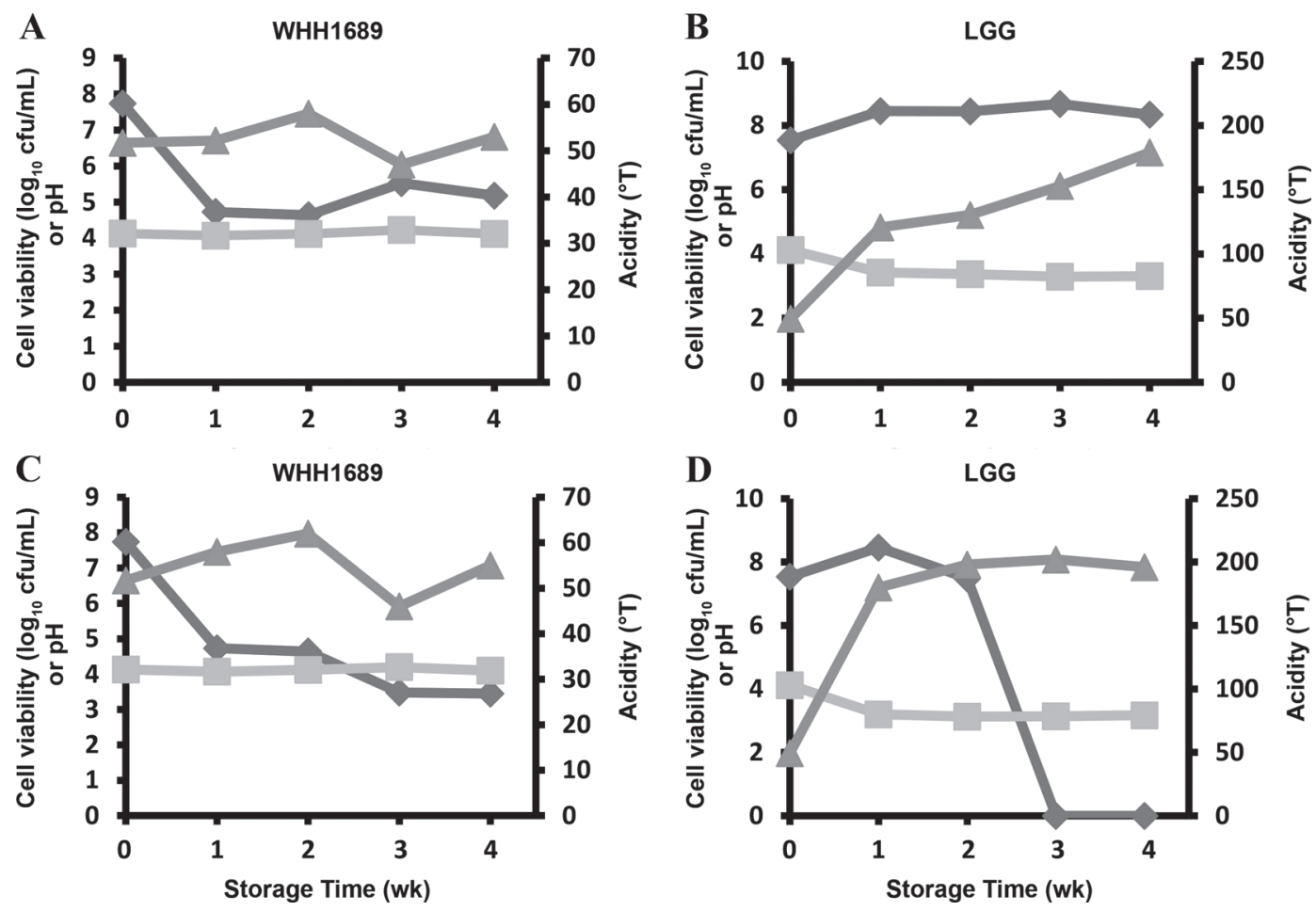

Figure 2. Cell viability of probiotics (left y-axis; $\bullet$ ), $\mathrm{pH}$ value (left y-axis; $\mathbf{\square}$ ), and acidity (right y-axis; $\mathbf{\Delta}$ ) of the product over 4 wk. Drinkable yogurt with (A) Lactobacillus reuteri WHH1689 strain stored at $28^{\circ} \mathrm{C}$, (B) Lactobacillus rhamnosus $\mathrm{GG}$ (LGG) strain stored at $28^{\circ} \mathrm{C}$, (C) WHH1689 strain stored at $37^{\circ} \mathrm{C}$, and (D) LGG strain stored at $37^{\circ} \mathrm{C}$.

LGG was used as a comparative probiotic strain. Figure 2 displays the viable cell count after $28^{\circ} \mathrm{C}$ or $37^{\circ} \mathrm{C}$ storage in the thinner drinkable yogurt. At $28^{\circ} \mathrm{C}$, the viable count of WHH1689 decreased 2 log during almost 1 mo of storage, whereas the $\mathrm{pH}$ and acidity slightly changed (Figure 2A). Strain LGG maintained stable viable counts at $28^{\circ} \mathrm{C}$ but acidity increased sharply from $50^{\circ} \mathrm{T}$ to $180^{\circ} \mathrm{T}$ (Figure $2 \mathrm{~B}$ ). At $37^{\circ} \mathrm{C}$, viable counts of WHH1689 were determined to be about $4 \log$ after 4 wk with a small change in $\mathrm{pH}$ and acidity (Figure $2 \mathrm{C}$ ). For LGG, a viable count was not observed after $3 \mathrm{wk}$ of incubation at $37^{\circ} \mathrm{C}$; acidity increased dramatically from $50^{\circ} \mathrm{T}$ to $180^{\circ} \mathrm{T}$ in wk 1 of incubation and then had a statistical tendency to increase thereafter (Figure 2D).
In the thicker drinkable yogurt, WHH1689 was incorporated and stored for nearly 5 mo. Table 1 shows that viable counts decreased from $9 \log$ to about $5 \mathrm{log}$ during $5 \mathrm{mo}$ of storage at $28^{\circ} \mathrm{C}$, and the $\mathrm{pH}$ and acidity changed slightly. At $37^{\circ} \mathrm{C}$, acidity changed slightly over 3 mo, with an obvious increase occurring at 5 mo. These results indicate that WHH1689 can survive in drinkable yogurt over a 3-mo shelf life at room temperature.

\section{Resistance of Lb. reuteri WHH1689 Under Conditions Simulating the Gastrointestinal Tract}

We studied the in vitro probiotic characteristics of strain WHH1689. As a potential probiotic candidate,

Table 1. The cell viability $\left(\log _{10} \mathrm{cfu} / \mathrm{mL}\right), \mathrm{pH}$ value, and acidity of the product over 5 mo at $28^{\circ} \mathrm{C}$ or $37^{\circ} \mathrm{C}^{1}$

\begin{tabular}{|c|c|c|c|c|c|c|}
\hline Storage time $(\mathrm{d})$ & \multicolumn{3}{|c|}{$28^{\circ} \mathrm{C}$} & \multicolumn{3}{|c|}{$37^{\circ} \mathrm{C}$} \\
\hline 30 & 6.98 & 4.08 & & 5.65 & 4.03 & \\
\hline 95 & 5.16 & 4.01 & 110.5 & 4.38 & 4.03 & 106.6 \\
\hline 145 & 4.89 & 4.08 & 105.1 & 4.65 & 3.85 & 133.1 \\
\hline
\end{tabular}

${ }^{1}$ Acidity $\left({ }^{\circ} \mathrm{T}\right)=\left(\mathrm{V}_{\mathrm{S}}-\mathrm{V}_{0}\right) \times 100 / \mathrm{M}_{\mathrm{S}}$, where $\mathrm{V}_{\mathrm{S}}$ is a volume of $0.1000 \mathrm{~mL} / \mathrm{L}$ of $\mathrm{NaOH}$ used to adjust the sample $\mathrm{pH}$ to $\mathrm{pH} 8.3, \mathrm{~V}_{0}$ is a volume of $0.1000 \mathrm{~mL} / \mathrm{L}$ of $\mathrm{NaOH}$ used to adjusted the water $\mathrm{pH}$ to $\mathrm{pH} 8.3$, and $\mathrm{M}_{\mathrm{S}}$ is grams of sample. 
Table 2. Viable cell counts $\left(\mathrm{n}=3\right.$, means $\left.\pm \mathrm{SD} ; \log _{10} \mathrm{cfu} / \mathrm{mL}\right)$ of Lactobacillus reuteri WHH1689 when challenged with low $\mathrm{pH}$ conditions, simulated gastric juice, bile salt, and pancreatin for different exposure times

\begin{tabular}{|c|c|c|c|c|c|}
\hline \multirow{2}{*}{$\begin{array}{l}\text { Exposure } \\
\text { time }(\mathrm{h})\end{array}$} & \multirow{2}{*}{$\begin{array}{c}\text { Control } \\
\text { (PBS, pH 7.2) }\end{array}$} & \multicolumn{2}{|c|}{ Low $\mathrm{pH}$ conditions } & \multicolumn{2}{|c|}{$\begin{array}{l}\text { Simulated gastric juice } 0.3 \% \\
\text { (wt/vol) pepsin }\end{array}$} \\
\hline & & $\mathrm{pH} 2$ & $\mathrm{pH} 3$ & $\mathrm{pH} 2$ & $\mathrm{pH} 3$ \\
\hline 0 & $9.70 \pm 0.06$ & & & & \\
\hline 1 & $9.71 \pm 0.01$ & $9.40 \pm 0.01$ & $9.60 \pm 0.03$ & $9.20 \pm 0.03$ & $9.58 \pm 0.03$ \\
\hline 2 & $9.32 \pm 0.23$ & $9.20 \pm 0.06$ & $9.18 \pm 0.03$ & $7.26 \pm 0.02$ & $9.09 \pm 0.01$ \\
\hline \multirow[t]{3}{*}{3} & $9.55 \pm 0.08$ & $6.77 \pm 0.19$ & $8.38 \pm 0.03$ & $6.99 \pm 0.01$ & $8.35 \pm 0.01$ \\
\hline & & \multicolumn{2}{|c|}{ Bile salt (pH 8) } & & \\
\hline & & $0.30 \%$ & $0.50 \%$ & \multicolumn{2}{|c|}{ Pancreatin (pH 8) } \\
\hline 0 & $9.47 \pm 0.10$ & & & \\
\hline 1 & $9.26 \pm 0.16$ & $9.26 \pm 0.11$ & $8.88 \pm 0.11$ & \multicolumn{2}{|c|}{$9.49 \pm 0.18$} \\
\hline 2 & $9.68 \pm 0.02$ & $9.51 \pm 0.03$ & $9.13 \pm 0.17$ & \multirow{2}{*}{\multicolumn{2}{|c|}{$\begin{array}{l}9.32 \pm 0.15 \\
9.02 \pm 0.40\end{array}$}} \\
\hline 3 & $9.02 \pm 0.40$ & $9.10 \pm 0.09$ & $8.74 \pm 0.05^{*}$ & & \\
\hline
\end{tabular}

Lb. reuteri WHH1689 should show resistance to gastrointestinal stress environments. The exposure of WHH1689 strain to a $\mathrm{pH} 3$ solution with or without pepsin resulted in a decrease in viable counts of about $1 \mathrm{log}$ after $3 \mathrm{~h}$ (Table 2). With exposure to $\mathrm{pH} \mathrm{2,} \mathrm{the}$ viable count decreased to $<0.5 \log$ in $2 \mathrm{~h}$ but decreased sharply after $2 \mathrm{~h}$ of incubation. Pepsin significantly affected viable cells at $\mathrm{pH} 2$, whereas no effect was observed in the $\mathrm{pH} 3$ solution. The strain displayed viable counts of $7 \mathrm{log}$ when incubated in $\mathrm{pH} 2$ solution with pepsin for $3 \mathrm{~h}$ compared with $9.7 \log$ initial viable cells. Strain WHH1689 was well resistant to $0.3 \%$ bile salts and pancreatin solutions at $\mathrm{pH} 8$; its viability was decreased by less than $0.5 \log$ unit after $3 \mathrm{~h}$ of exposure, as shown in Table 2. In general, the physiological concentrations of human bile range from 0.3 to $0.5 \%$. With exposure to $0.5 \%$ bile salts, the viable counts of WHH1689 decreased by less than 1 log during the 3-h incubation.

\section{Adhesion Assay}

We examined the ability of WHH1689 to adhere to HT-29 epithelial cells. The WHH1689 strain had an adherence of $4.60 \% \pm 1.67$ to HT-29 cells, whereas strain LGG had an adherence of $4.00 \% \pm 1.22$. Adhesion of probiotic strains to human intestinal mucosa is regarded as a prerequisite characteristic for potential probiotic microorganisms. In this study, WHH1689 showed a high ability to adhere to the epithelial cell line.

\section{Antimicrobial Activity}

For the antimicrobial assay, WHH1689 showed significant inhibitory activity against all 4 target pathogenic bacteria (Table 3). The diameter of growth inhibition zones was larger for WHH1689 than for antibacterial agents (polymyxin B or nisin) as positive controls.

\section{Regulatory Effect of $L b$. reuteri on the Intestinal Flora in a DSS-Induced Mouse Model}

In vivo studies focusing on the regulatory effect on intestinal flora were carried out using a DSS-induced mouse model. After the first $14 \mathrm{~d}$ of treatment, fecal samples of groups 1 to 4 were collected. The culturable

Table 3. Inhibition zones (mm; mean $\pm \mathrm{SD}$ ) of 4 intestinal pathogens by Lactobacillus reuteri WHH1689

\begin{tabular}{lcccc}
\hline & \multicolumn{4}{c}{ Pathogen } \\
\cline { 2 - 5 } Treatment & Escherichia & Salmonella & Shigella & Staphylococcus \\
paratyphi & flexneri & aureus \\
\hline WHH1689 & $19.0 \pm 1.7$ & $15.7 \pm 2.3$ & $12.0 \pm 0.0$ & $11.0 \pm 0.0$ \\
Control: $15 \mu \mathrm{g} / \mathrm{mL}$ Polymyxin B & 12.0 & 10.0 & 10.0 & - \\
Control: $1 \% \mathrm{nisin}$ & - & - & - & 0.0 \\
\hline
\end{tabular}




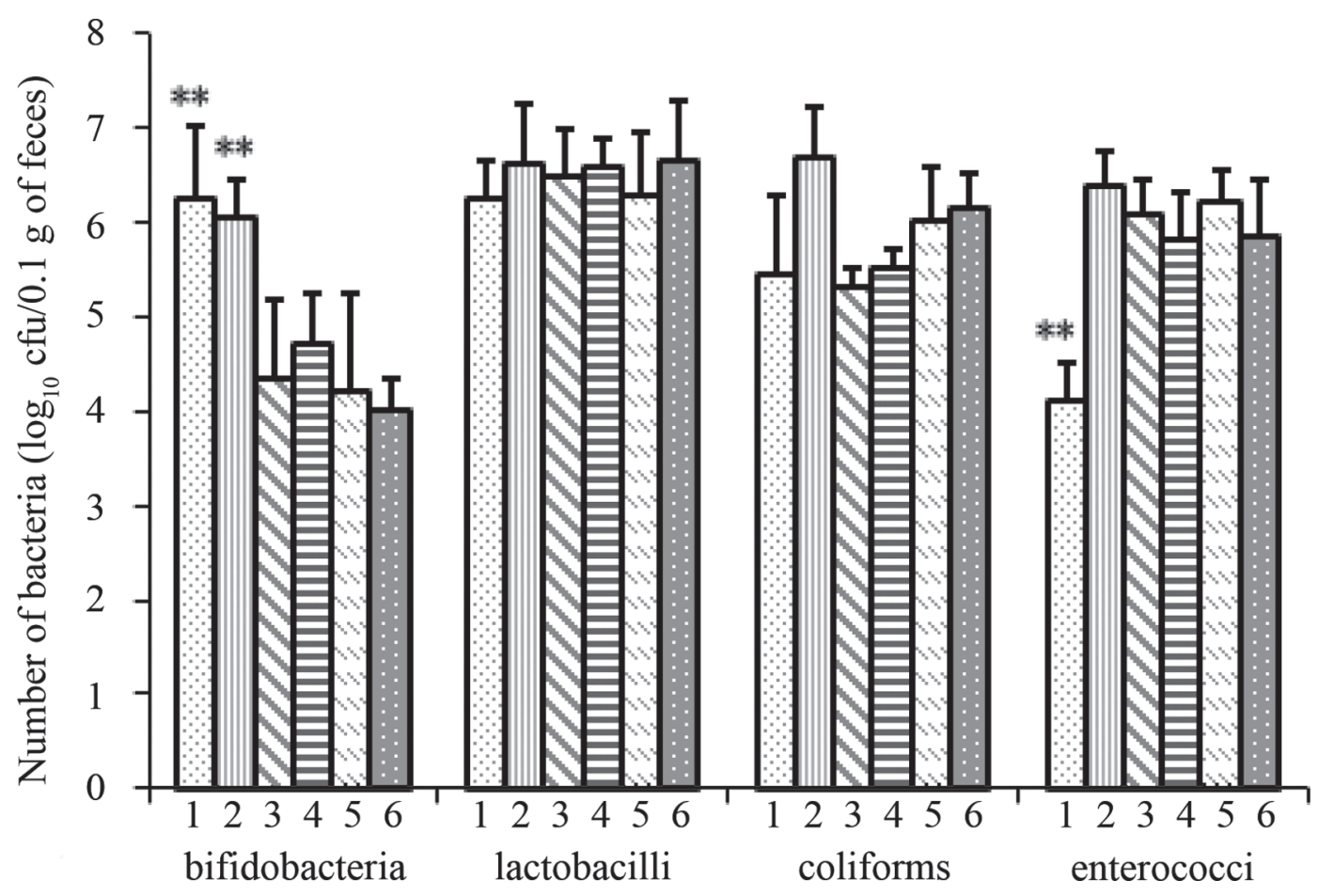

Figure 3. Regulatory effect of probiotics on the intestinal flora of dextran sulfate sodium (DSS)-induced mice including bifidobacteria, lactobacilli, coliforms, and enterococci. Group $1=$ control, no probiotic and no DSS administration; group 2 and $3=$ pretreatment with $10^{9}$ and $10^{10}$ cfu, respectively, of Lactobacillus reuteri in the first $14 \mathrm{~d}$, then given the DSS solution and L. reuteri administration; group $4=$ pretreatment with $10^{9}$ cfu of Lactobacillus casei, in the first $14 \mathrm{~d}$, then given the DSS solution and L. casei administration; group $5=$ colitis control group, only given the DSS solution without probiotic treatment; and group $6=$ no pretreatment with probiotics in the first $14 \mathrm{~d}$, then given the DSS solution and $10^{9}$ cfu of $L b$. reuteri. Error bars represent the mean $\pm \mathrm{SD}, \mathrm{n}=10$. ${ }^{* *} P<0.05$ compared with group 5 .

bacteria, including total lactobacilli, total bifidobacteria, coliforms, enterococci, and C. perfringens, were counted. No significant difference was found between probiotic-treated groups (groups 2, 3, and 4) and the control group (group 1, data not shown). Thus, $L b$. reuteri WHH1689 and Lb. casei Shirota had no significant effect on the intestinal flora in wild mice. In the DSS-treated mice, pretreatment administration of $10^{7}$ cfu of $L b$. reuteri/animal (group 2) was found to dramatically increase the number of bifidobacteria (Figure 3 ) in the fecal sample compared with the colitis group (group 5). When the dose of Lb. reuteri was increased to $10^{8} \mathrm{cfu}$ (group 3), no influence of the intestinal flora was found. Mice in group 6 received $L b$. reuteri during DSS administration, and no difference was found in intestinal flora compared with the colitis group. With pretreatment with L. casei at $10^{7} \mathrm{cfu} /$ animal (group 4 ), the number of bifidobacteria was slightly increased compared with the colitis group (group 5). Numbers of total lactobacilli, coliforms, and enterococci did not differ among the probiotic-treated groups and the colitis group. The number of $C$. perfringens in feces from all groups of mice was always zero (data not shown).

\section{DISCUSSION}

To exert a beneficial health effect, the level of probiotics in products must be at least $10^{6} \mathrm{cfu} / \mathrm{mL}$ before consumption (Nualkaekul et al., 2012). Therefore, conditions that keep the probiotics viable during storage are very important. Currently in the dairy industry, probiotics in liquid products such as yogurt or fruit juice are normally stored in refrigerated conditions and have even been encapsulated (Chaikham, 2015). The main purpose of the present study was to identify suitable probiotic strains for incorporation into dairy products that could negate the need for low temperature storage. We collected highland barley wine in Tibet, on the hypothesis that the very high altitude and alcoholic environment might induce unusual, but useful, characteristics of bacterial strains. Lactobacillus reuteri WHH1689 was selected because it has a very weak lactose metabolic pathway and should not cause serious post-acidification during storage. In the storage stability test, 2 types of drinkable yogurt were used and LGG was used as a negative control strain. The results showed that at $28^{\circ} \mathrm{C}$, both WHH1689 and LGG 
survived well over $4 \mathrm{wk}$ of storage, but LGG strain caused very serious acidification, which resulted in a change of the texture of the product. At $37^{\circ} \mathrm{C}$, LGG lost viability in $3 \mathrm{wk}$, whereas WHH1689 demonstrated a very slow decline over $4 \mathrm{wk}$. In the thicker yogurt during $5 \mathrm{mo}$ of storage at $28^{\circ} \mathrm{C}$ or $37^{\circ} \mathrm{C}$, WHH1689 bacteria retained viability of $5 \mathrm{log}$. Thus, $L b$. reuteri WHH1689 exhibited demonstrable and persistent survivability at room temperature storage. Further experimentation is underway to improve the survivability of WHH1689 in drinkable yogurt.

For newly isolated lactobacillus strains, in vitro experiments are conducted to evaluate probiotic properties. In this study, low $\mathrm{pH}$ and bile content were used to evaluate the tolerance of strain WHH1689 to the acidic environment of the stomach and upper part of the intestines. The results showed that $L b$. reuteri WHH1689 could survive under conditions simulating the gastrointestinal tract, which indicates that the probiotic may survive transit through the human gastrointestinal tract. In the adhesion assay, LGG, which has been shown in several previous studies to bind to enterocytes (Andersson, et al., 2001; van Ossowski et al., 2010; Lee et al., 2011), was used as a positive control. Strain WHH1689 exhibited similar adherence compared with the positive control strain, which may indicate that WHH1689 could confer beneficial effects on the host.

We also investigated WHH1689 functionality in vivo. Changes in the composition of the mucosal-associated and fecal microbiota in patients with inflammatory bowel disease (IBD) have previously been demonstrated (Manichanh et al., 2006; Frank et al., 2007). The DSSinduced mouse model has many clinical and pathological similarities to human IBD (Wirtz et al., 2017). In this work, we studied the effect of the probiotic in the intestinal flora of the DSS-induced mice. Lactobacillus casei Shirota has been shown to have beneficial effects in numerous murine disease models via host immune modulation (Matsuzaki et al., 2007) and was used as a control for comparison. Pretreatment (i.e., before DSS induction) with $10^{7}$ cfu per animal of WHH1689 resulted in a significant increase of total bifidobacteria, which are beneficial to human health, whereas counts of total lactobacilli were not changed. Pretreatment with a large dose of WHH1689 had no effect on the intestinal flora. Pretreatment with $10^{7}$ cfu of LcS per animal had only a slight effect on the intestinal flora. Therefore, WHH1689 might have a better benefit for humans in intestinal flora viability and health. Before DSS administration, the intestinal flora of mice treated with WHH1689 or LcS did not differ from that of untreated animals. Previous studies showed similar results. Xia et al. (2011) found that Lactobacillus plantarum LP-Olly could improve the intestinal flora in IL-10 ${ }^{-/-}$mice but had no effect on wild-type mice.

Further research is currently underway in our laboratory to determine the mechanisms responsible for the high viability of strain WHH1689 under RT storage. Genomic sequencing and analysis is also being pursued.

This study showed that Lb. reuteri WHH1689 is resistant to conditions simulating the gastrointestinal tract and it beneficially modified the intestinal microflora in an experimental colitis mouse model, which merits consideration as a probiotic. At RT, this strain has high viability and low post-acidification, implying its potential in a room-temperature-storage drinkable probiotic yogurt.

\section{ACKNOWLEDGMENTS}

The authors thank Michael J. Murphy (State University of New York) for careful proofreading and suggesting changes in this manuscript. This work was supported by the Major Science and Technology Projects of Zhejiang Province (China; 2015C02039).

\section{REFERENCES}

Andersson, H., N. G. Asp, A. Bruce, S. Roos, T. Wadström, and A. E. Wold. 2001. Health effects of probiotics and prebiotics: A literature review on human studies. Scand. J. Nutr. 45:58-75.

Argyri, A. A., G. Zoumpopoulou, K. A. Karatizas, E. Tsakalidou, G. J. E. Nychas, E. Z. Paganou, and C. C. Tassou. 2013. Selection of potential probiotic lactic acid bacteria from fermented olives by in vitro tests. Food Microbiol. 33:282-291.

Balthazar, C. F., C. A. Conte Júnior, J. Moraes, M. P. Costa, R. S. L. Raices, R. M. Franco, A. G. Cruz, and A. C. O. Silva. 2016. Physicochemical evaluation of sheep milk yogurts containing different levels of inulin. J. Dairy Sci. 99:4160-4168.

Batista, A. L. D., R. Silva, L. P. Cappato, C. N. Almada, R. K. A. Garcia, M. C. Silva, R. S. L. Raices, D. B. Arellano, A. S. SantAna, C. A. Conte Jr., M. Q. Freitas, and A. G. Cruz. 2015. Quality parameters of probiotic yogurt added of glucose oxidase compared to commercial products through microbiological, physical-chemical and metabolic activity analyses. Food Res. Int. 77:627-635.

Chaikham, P. 2015. Stability of probiotics encapsulated with Thai herbal extracts in fruit juices and yoghurt during refrigerated storage. Food Biosci. 12:61-66.

Charnchai, P., S. S. Jantama, C. Prasitpuriprecha, S. Kanchanatawee, and K. Jantama. 2016. Effects of the food manufacturing chain on the viability and functionality of Bifidobacterium animalis through simulated gastrointestinal conditions. PLoS One 11:e0157958.

FAO/WHO. 2006. Probiotics in Food, Health and Nutritional Properties and Guidelines for Evaluation. FAO Food Nutr. Pap. Food and Agriculture Organization of the United Nations (FAO), Rome, Italy.

Frank, D. N., A. L. St Amand, R. A. Feldman, E. C. Boedeker, N. Harpaz, and N. R. Pace. 2007. Molecular-phylogenetic characterization of microbial community imbalances in human inflammatory bowel diseases. Proc. Natl. Acad. Sci. USA 104:13780-13785.

Garcia, E. F., W. A. Luciano, D. E. Xavier, W. C. da Costa, K. de Sousa Oliveira, O. L. Franco, M. A. de Morais Júnior, B. T. Lucena, R. C. Picão, M. Magnani, M. Saarela, and E. L. de Souza. 2016. Identification of lactic acid bacteria in fruit pulp processing byproducts and potential probiotic properties of selected lactobacillus strains. Front. Microbiol. 7:1371. 
Guo, X. H., J. M. Kim, H. M. Nam, S. Y. Park, and J. M. Kim. 2010. Screening lactic acid bacteria from swine origins for multistrain probiotics based on in vitro functional properties. Anaerobe $16: 321-326$.

Hill, C., F. Guarner, G. Reid, G. R. Gibson, D. J. Merenstein, B. Pot, L. Morelli, R. B. Canani, H. J. Flint, S. Salminen, P. C. Calder, and M. E. Sanders. 2014. Expert consensus document: The International Scientific Association for Probiotics and Prebiotics consensus statement on the scope and appropriate use of the term probiotic. Nat. Rev. Gastroenterol. Hepatol. 11:506-514.

Hill, D., I. Sugrue, E. Arendt, C. Hill, C. Stanton, and R. P. Rossa 2017. Recent advances in microbial fermentation for dairy and health. F1000Res. 6:751-759.

Jiang, J., Z. Lou, S. Ng, C. Luobu, and D. Ji. 2009. The current municipal solid waste management situation in Tibet. Waste Manag. 29:1186-1191.

Kim, Y., S. Oh, S. Park, and S. H. Kim. 2009. Interactive transcriptome analysis of enterohemorrhagic Escherichia coli (EHEC) O157:H7 and intestinal epithelial HT-29 cells after bacterial attachment. Int. J. Food Microbiol. 131:224-232.

Larkin, M. A., G. Blackshields, N. P. Brown, R. Chenna, P. A. McGettigan, H. McWilliam, F. Valentin, I. M. Wallace, A. Wilm, R. Lopez, J. D. Thompson, T. J. Gibson, and D. G. Higgins. 2007. Clustal W and Clustal X version 2.0. Bioinformatics 23:2947-2948.

Lee, J., H. S. Yun, K. W. Cho, S. Oh, S. H. Kim, T. Chun, B. Kim, and K. Y. Whang. 2011. Evaluation of probiotic characteristics of newly isolated Lactobacillus spp.: Immune modulation and longevity. Int. J. Food Microbiol. 148:80-86.

Manichanh, C., L. Rigottier-Gois, E. Bonnaud, K. Gloux, E. Pelletier, L. Frangeul, R. Nalin, C. Jarrin, P. Chardon, P. Marteau, J. Roca, and J. Dore. 2006. Reduced diversity of faecal microbiota in Crohn's disease revealed by a metagenomic approach. Gut 55:205-211.

Matsuzaki, T., A. Takagi, H. Ikemura, T. Matsuguchi, and T. Yokokura. 2007. Intestinal microflora: Probiotics and autoimmunity. J. Nutr. 137:798S-802S.

Mesas, J. M., M. C. Rodríguez, and M. T. Alegre. 2011. Characterization of lactic acid bacteria from musts and wines of three consecutive vintages of Ribeira Sacra. Lett. Appl. Microbiol. 52:258-268.

Nami, Y., N. Abdullah, B. Haghshenas, D. Radiah, R. Rosli, and A. Y. Khosroushahi. 2014. Probiotic potential and biotherapeutic effects of newly isolated vaginal Lactobacillus acidophilus 36YL strain on cancer cells. Anaerobe 28:29-36.

Nualkaekul, S., D. Lenton, M. T. Cook, V. V. Khutoryanskiy, and D. Charalampopoulos. 2012. Chitosan coated alginate beads for the survival of microencapsulated Lactobacillus plantarum in pomegranate juice. Carbohydr. Polym. 90:1281-1287.

Saad, N., C. Delattre, M. Urdaci, J. M. Schmitter, and P. Bressollier. 2013. An overview of the last advances in probiotic and prebiotic field. LWT Food Sci. Technol. 50:1-16.

Shah, N. P. 2000. Probiotic bacteria: Selective enumeration and survival in dairy foods. J. Dairy Sci. 83:894-907.

Tamura, K., D. Peterson, N. Peterson, G. Stecher, M. Nei, and S. Kumar. 2011. MEGA5: Molecular evolutionary genetics analysis using maximum likelihood, evolutionary distance, and maximum parsimony methods. Mol. Biol. Evol. 28:2731-2739.

van Ossowski, I., J. Reunanen, R. Satokari, S. Vesterlund, M. Kankainen, H. Huhtinen, S. Tynkkynen, S. Salminen, W. M. De Vos, and A. Palva. 2010. Mucosal adhesion properties of the probiotic Lactobacillus rhamnosus GG SpaCBA and SpaFED pilin subunits. Appl. Environ. Microbiol. 76:2049-2057.

Wang, X., H. Ren, D. Liu, B. Wang, W. Zhu, and W. Wang. 2013. $\mathrm{H}(+)$-ATPase-defective variants of Lactobacillus delbrueckii ssp. bulgaricus contribute to inhibition of postacidification of yogurt during chilled storage. J. Food Sci. 78:M297-M302.

Wirtz, S., V. Popp, M. Kindermann, K. Gerlach, B. Weigmann, S. Fichtner-Feigl, and M. F. Neurath. 2017. Chemically induced mouse models of acute and chronic intestinal inflammation. Nat. Protoc. 12:1295-1309.

Xia, Y., H. Q. Chen, M. Zhang, Y. Q. Jiang, X. M. Hang, and H. L. Qin. 2011. Effect of Lactobacillus plantarum LP-Onlly on gut flora and colitis in interleukin-10 knockout mice. J. Gastroenterol. Hepatol. 26:405-411.

Zhang, J., X. Zhang, L. Zhang, Y. Zhao, C. Niu, Z. Yang, and S. Li 2014. Potential probiotic characterization of Lactobacillus plantarum strains isolated from Inner Mongolia "Hurood" cheese. J. Microbiol. Biotechnol. 24:225-235.

Zhong, Z. M., Z. X. Shen, and G. Fu. 2016. Response of soil respiration to experimental warming in a highland barley of the Tibet. Springerplus 5:137-146. https://doi.org/10.1186/s40064-016-1761-0. 